\title{
Influence of the Supervision Related Background Variables on the Supervisees' Supervision Experiences at Postgraduate Level
}

\author{
Tooba Saleem* \\ Nasir Mahmood ${ }^{* *}$
}

\begin{abstract}
This research aims to investigate the influence of some supervision related background variables on the supervisees' supervision experiences during their research at postgraduate level. We conducted a survey from $(N=422)$ supervisees using Supervisor-Supervisee. Relationship Questionnaire (SSRQ, 65 items) scored on six point scale. The items of SSRQ were developed on six supervision aspects to find the supervision related experiences in addition to the selected background variables. The subscale wise content validity and reliability of the SSRQ was ensured. Inferential statistics were applied to achieve the main objectives of the research. The findings of the research highlighted the importance of supervisors' expertise and research skills in the supervisees' area of research. The supervisees who were not given choice for the selection of the supervisor have reported negative supervision experiences. Giving choice to the selection of a supervisor can improve the supervision experiences of supervisees and can minimize the potential personality and research interest related anomalies. Supervisees from the social sciences disciplines reported the problem of workload management during the supervision process. On the basis of findings it is suggested that supervision allotment procedure, alignment between supervisors' area of specialization and supervisee research topic and discipline specific supervision trainings may be initiated.
\end{abstract}

Keywords: Research supervision, supervision experiences, quality of supervision, supervisor-supervisee relationship

\footnotetext{
* Lecturer, Secondary Teacher Education Department, Allama Iqbal Open University, Islamabad. Email: tooba.saleem@aiou.edu.pk

** Professor, Elementary Teacher Education and Early Childhood Education Department, Allam Iqbal Open University, Islamabad. Email: nasir.mahmood@aiou.edu.pk
} 


\section{Introduction}

One basic agenda of the Higher Education Commission (HEC) at the time of its establishment in 2002 was "to double enrollment in higher education from $2.2 \%$ to $5 \%$ by the end of 2010" (Halai, 2011). As result of which a substantial growth was observed where "the number of $\mathrm{PhD}$ students enrolled in universities has increased over 40 per cent (from 6,937 to 9,858 students) last year and more than 28,122 students were registered for the $\mathrm{M}$. Phil level programs with an increase of 65 percent (from 16,960 to 28,122) over the past two years" (Noor, 2013). While in higher education institutions against these enrolled candidates the pool of upcoming full-time faculty with $\mathrm{PhD}$ degree is less than one third (34444 i.e. $26.86 \%$ ) of the total (9253) faculty members recruited till 2012-2013 (HEC, 2015).

Against this continuously increasing number of enrolled students in higher education institutions, the resources and proportion of $\mathrm{PhD}$ faculty members in Pakistan is not adequate. Consequently, it has increased the workload of the existing supervisors (Iqbal, Saeed \& Abbas, 2012).

Some institutions are found eager to enroll the higher degree candidates but do not schedule appropriate time from the teaching loads of their staff members for supervision. Consequently, supervision is expected as a sideline activity in supervisors' own research time (Connell, 1985). The situation is still true in the context of Pakistan where the teaching workload is not scheduled according to the supervision workload. Traditionally, the supervision workload of teachers is not considered while scheduling their teaching hours and institutional responsibilities. However, it consumes a considerable time of academics who supervise at postgraduate level.

Moreover, the increasing workload sometimes also hinders the supervisors from taking up research issues related to their expertise or supervising directly within their own area of specialization or some supervisors are being allocated students whose research interests are peripheral to their own (Ives \& Rowley, 2005). However, supervision workload at times results in compromising the quality of research while maintaining the creativity and relevance of knowledge needed to accommodate a larger number of supervisees, which has led to insipid and repetitive researches, and publication of theses on such topics which are outdated or not related to our current social problems (Javed, 2014). In addition, supervisors with substantial workload are unable to give proper time to their supervisees (Abiddin, Ismail \& Ismail, 2011; Eley \& Jennings, 2004; Spear, 2000). 
Iqbal, Saeed and Abbas (2012) revealed some doctoral level supervision problems in Pakistan that supervisors don't give proper time to the scholars due to their academic workload. Specially, in public sector universities, the number of $\mathrm{PhD}$ faculty is insufficient and teachers are found overloaded. Similar findings were revealed in the Indian research (Nevada, 2009) that supervisors are very busy with other work. While performing other institutional administrative and teaching responsibilities, it becomes a difficult task for supervisors to spend appropriate time in supervision by arranging regular meetings with supervisees, to check their work timely and giving specific feedback related to the weaknesses and flaws in their work. To monitor the working progress of their supervisees in the right direction becomes difficult.

Hence, in managing this workload, sometimes the one important element of "quality" in supervising the research is being compromised which is already weak area in the higher education institutions of Pakistan (Virk, 2003). Further, the increase in enrollment has been compounded with broadening of the disciplines and simultaneously the research areas in which supervisors are expected to provide supervision support and expertise. This has doubled the responsibility of supervisors in case when they have to supervise a supervisee other than their specialized field of research that definitely consumes more time of supervisors as compared to time that needs to supervise the supervisees from the same discipline and research area.

On the other hand, candidates at postgraduate level have limited choices for the selection of supervisors in their specific field of research or area of interest. Sometimes students feel themselves bound to compromise to work on an area of research other than their field or interest. Otherwise during research they may have to face issues specifically related to the intellectual support from their supervisors (Ives \& Rowley, 2005).

Another issue is the allocation of supervisor which is done by the decision of departmental doctoral program committees' members. In the latter case, candidates are bound to work with a supervisor probably with whom they have a mismatch of academic expertise or personality traits. Such types of situations can also influence the supervision experiences of supervisees regarding their different supervision needs. However, these practices vary from one institution to other institution and within one institution are also not practiced uniformly (Saleem, 2014).

Although, globally there can be found a bulk of literary work related to the contemporary issues of postgraduate supervision which exhibited 
the greater concern of the academics about improving supervision practices regarding their context specific problems. In the last decade, more approaches that are practical have been made to address the changing needs, context and understanding of research supervision in different dimensions. Subsequently, to improve the quality of research supervision at higher education level different countries have made different efforts. In United Kingdom (UK) guidelines are set for the supervisors and all supervisors are expected to have undergone training in supervision, which is usually in house, in addition a "Code of Practice" was also developed by Quality Assurance Agency (QAA, 2004) for research programs in UK. Besides that, some universities develop workload models to make sure that a supervisor dedicates sufficient time in support of each doctoral candidate. In addition different countries including France, New Zealand, Australia and UK initiated different type of training programs to improve the effectiveness of supervision practices according to their problems and needs as reported in "Global Review on Higher Education, Research and Knowledge" (Eggins, 2008).

There is need to investigate the factors that influence the research supervision in the context of those countries where the research supervision practices are still undefined and non-routinized. As in the higher education system of Pakistan where the institutions still did not cross the threshold concept of research supervision presented by Connell (1985) who presented the concept of research supervision as "the most advanced level of teaching in the educational system" that is evident in the context of Pakistan in the absence of any coursework, degree or licensure exam that trains an academic to become a supervisor (Halai, 2011). Moreover, legislatively or at the institutional level, no guidelines, code of supervision or practices can be found for supervisors' training or any induction course for supervisees to meet their research related needs. The concept of research supervision is still ignored and is being compromised in higher education institutions of Pakistan. A few researchers (Iqbal, Saeed \& Abbas, 2012; Mahmood, 2011; Yousaf \& Ashraf, 2010) have thrown light on the research supervision issues and experiences at postgraduate level in Pakistan.

In the global and local perspective, the research generally focused on the post-supervisory relationship issues that a supervisee faces after supervision has begun. Hence, the issues during the supervision process or the potential problems in the supervisory relationship have been significantly highlighted that could hamper the development or success of research projects at postgraduate level. Ignoring those important 
research supervision related background variables that can be considered as a primer of supervisor-supervisee relationship and subsequently helpful to manage the supervision process issues and improving supervision experiences will support the weak supervision culture that may cause major breakdown. In this context, the present research can provide a concrete basis for establishing precautionary variables of research supervision process and may help the stakeholders to avoid negative supervision experiences. This is the situation, which inspired the researcher to investigate in this area.

\section{Review of Literature}

\section{Supervisor-supervisee Relationship and Supervision Experiences}

In research supervision process the relationship between supervisee and supervisor can be considered as the most visible layer that affects and is affected by all factors within the domain of supervision (Grant, 2003; Holloway, 1995; Lynch, 2008). It is important to unpack the supervision process for examining the supervision aspects. Through the lens of these supervision aspects it becomes evident to investigate the supervision experiences associated with supervisor-supervisees relationship that contributes towards the quality of supervision as highlighted in the literature.

Project management is one of the most important aspect of supervision for supervisors that is highlighted in literature in terms of structuring realistic time frames, monitoring work planning and managing resources. In this perspective, Philips and Pugh (2010) also recognized the role of supervisor in managing the research project by providing structure of meeting, deadlines. Rugg \& Petre (2004) emphasized on deadline creation and enforcement. Taylor \& Beasley (2005) also indicated the poor time management skills as a hurdle to complete the project on time particularly, arts, humanities or social sciences. They also emphasized the role of supervisors in doing favor to their supervisees particularly in the beginning of the research project, by setting realistic deadlines and asserting them to meet. Wisker (2005) pointed out that in research supervision process the supervisor's task becomes directing and managing project.

Some other essential factors are also emphasized as part of successful research supervision process like intellectual support by supervisors in developing critical thinking in supervisees and providing 
critical constructive feedback (Lee, 2008; Pearson, 2005). Spear (2000) suggested that supervisors should thoroughly read out the written drafts of their supervisees with given constructive feedback and found it an essential element for the supervisee's intellectual grooming. In this perspective, Ives and Rowley (2005) emphasize the importance of matching supervisors to students in terms of both topic expertise to provide relevant feedback and ensuring successful supervisor-supervisee working relationships.

In addition, Kam (1997) proposed a useful set of domains for assessing the quality of the supervision relationship by factor analytic investigation of the level of student satisfaction with the supervisory process came to find that student responses were consistently clustered around three emergent factors: 'work organization and problem solving', characterized by work tasks that denote efforts made to assure work quality in the research process, 'research preparation' representing work tasks typical of those found during the early part of the research process, and 'communication' standing for work tasks centered on communication and interaction at different levels. He concluded that "a supervisor's familiarity with her or his students' area of research is also an important attribute of quality supervision, especially in the eyes of those needing substantial guidance in work organization and problem solving" (p.100).

Having pertinent research skills and expertise for a supervisor in supervisee's research topic is one of the most essential supervision aspects at postgraduate level. Cullen, Pearson, Saha \& Spear (1994) in this perspective also produced a list of good supervisor including the characteristics: approachable and friendly, supportive, positive attitude, open minded, prepared to accept acknowledge error, organized, thorough, and stimulating and conveys enthusiasm for research. Ismail, Majid \& Ismail (2013) explored the supervision role from the supervisees' side particularly focusing on the tensions that arose between research students and their supervisors when faced problems at different stages of their doctoral journeys. The findings of the study highlighted the three main issues of supervisees: lack of positive communication, lack of necessary supportive skills and power conflicts. Salmon (1992) declared that personal support was the most important dimension of the supervisory relationship.

A survey study was conducted in Pakistan by Iqbal, Saeed and Abbas (2012) the finding of the study identified some supervision problems at doctoral level research in which most of the students have opined that supervisors did not give proper time to the scholars due to 
their academic work load. Similar findings were revealed in the study of Nevada (2009) who found that supervisors are very busy with other work.

Haksever and Manisali (2000) found that supportive skills of supervisors regarding personal, technical and administrative issues of supervises during supervision were found to be as useful to investigate the supervision experiences of supervisees at postgraduate level.

\section{Supervisees' Supervision Experiences and Background Factors}

With reference to the above mentioned literature that particularly focuses on the factors that influence the supervision experiences of supervisees during supervision process. The literature on supervision problems also shed light upon some important background variables such as supervisee's discipline of study (Cullen et al., 1994). Seagram, Gould \& Pyke, (1998) in this context found that the faster times and higher completion rates associated with the sciences appeared to arise from the fact that science students were observed meeting more frequently with their supervisors, make an early start on their dissertation research compared to humanities Ives \& Rowley (2005) emphasized on the alignment between supervisor's area of specialization and supervisee's research topic and supervisees' choice in supervisor allotment procedure as the important background variables (Holloway et al., 1995)can influence the supervision experiences of supervisees at postgraduate level.

Despite the above mentioned factors that influence the supervisory experiences in the different regions have been observed with ample evidence there need to explore the supervision experiences with respect to the selected background in such regions where the culture of research supervision is not much flourished and the manifestations of supervisory relationship is different from the western culture. For instance, the concept of respect of supervisor in Asian culture is at times becomes a barrier to well placed a supervisee's ideas and arguments. Generally, the receptive behavior of research candidates on the other hand is also a hindrance in this perspective.

In this situation, studying those background factors can provide a concrete basis to preclude the potential negative supervision experiences that have been faced after getting into supervisory relationship. Hence, quality of supervision can be improved by ensuring the synergy between research related background variables of supervisees and their supervision experiences. 


\section{Research Questions}

In the above explained context, our research aims to investigate the potential influence of background variables on supervisees' supervision experiences during their research at postgraduate level by taking up the following research questions:

1. Does a mismatch between supervisor's area of specialization and the supervisee's research area affect the supervision experiences of the supervisees?

2. Does the supervisor allotment procedure influence the supervision experiences of supervisees?

3. What discipline specific supervision problems are experienced by supervisees during supervisor- supervisee relationship?

\section{Methodology}

The Researchers used survey design to investigate the potential influence of research supervision related background variables on the supervisees' supervision experiences during the relationship with their supervisor at postgraduate level. We collected data from $(N=422)$ supervisees, that were explicitly approached once during this research. A total of (8) public and (4) private, Universities and Degree Awarding Institutions (DAIs) of Punjab were selected on the basis of postgraduate level programmes offering in multiple disciplines.

Supervisees were drawn from the six disciplines: Education, Physical Sciences, Life Sciences, Social Sciences, Management Sciences, and Arts and Humanities. Faculties were observed and selected with respect to the variation in their mode of research (field research, desk based research, laboratory or experimentation etc.) and the nature of their research supervision.

The selection of supervisees was based on a number of research supervision related background variables which were supposed to influence the supervision experiences of supervisees associated with their supervisor. These background variables were identified as part of demographic profile of the supervisees included in the sample. Among the sample of 422 supervisees with their distribution, are given below in table 1 . 
Table 1

Demographic Characteristics of Supervisees

\begin{tabular}{|c|c|c|}
\hline Demographic Characteristics of Supervisees & $N=422$ & Non-response Cases \\
\hline \multicolumn{3}{|l|}{ Discipline of Study } \\
\hline Education & $96(23 \%)$ & $10(3 \%)$ \\
\hline Physical Sciences & $68(16 \%)$ & \\
\hline Life Sciences & $120(28 \%)$ & \\
\hline Social Sciences & $86(20 \%)$ & \\
\hline Management Sciences & $31(7 \%)$ & \\
\hline Arts and Humanities & $11(3 \%)$ & \\
\hline \multicolumn{3}{|l|}{ Gender } \\
\hline Male & $128(30 \%)$ & \\
\hline Female & $291(69 \%)$ & $3(1 \%)$ \\
\hline \multicolumn{3}{|l|}{ Procedure of Supervisor Allotment } \\
\hline Own choice & $275(65 \%)$ & \\
\hline By department & $138(33 \%)$ & $9(2 \%)$ \\
\hline \multicolumn{3}{|l|}{$\begin{array}{l}\text { Alignment between Research Topic and } \\
\text { Supervisor's Area of Specialization }\end{array}$} \\
\hline Completely different & $41(10 \%)$ & $8(2 \%)$ \\
\hline Different to some extent & $69(16 \%)$ & \\
\hline Similar to some extent (having published & $152(36 \%)$ & \\
\hline work) & $152(36 \%)$ & \\
\hline Exactly same & & \\
\hline
\end{tabular}

\section{Instrument}

For describing the supervisees' supervision experiences (SSE) with respect to the different ancillary variables, we developed a SupervisorSupervisee Relationship Questionnaire (SSRQ) for supervisees. The SSRQ was based on the theoretical framework derived from the literature on postgraduate supervision to tap the construct with six main factors: 1) Project management, 2) Intellectual support, 3) Pertinent research skills, 4) Interpersonal communication skills, 5) Workload management and 6) Supportive skills.

The items of the SSRQ were developed on the indicators drawn from these six main aspects of supervision as mentioned earlier in the reviewed literature to determine the quality of supervision. The SSRQ comprised two parts: The first part was developed to analyze the demographic profile of supervisees while the second part comprised 65 forced choice items using a six-point scale of agreement. The items were directly related to the supervision aspects of supervisors contributing to quality of supervision as experienced by their supervisees. 


\section{Validity and Reliability of the Instrument}

Expert opinion was taken from the $\mathrm{PhD}$ faculty members and supervising at the higher education level to ensure the content validity (Lawshe, 1975) of the Supervisor-Supervisee Relationship Questionnaire (SSRQ). According to Shultz and Whitney (2005, p. 88) "the content approach to test validation examines the degree to which the items that comprise the test are representative of entire theoretical content the test is intended to assess". Two measures are taken for the content validation purpose: Content Validity Ratio (CVR) and Content Validity Index (CVI). We asked 8 Subject Matter Experts (SMEs) to examine the representativeness and relevance of the entire theoretical content (SSRQ) that was intended to examine the supervision experiences of supervisees during the supervisory relationship. CVR provides an item level analysis of validity to determine the index of the content validity of SSRQ as a whole, while the mean CVR across retained items is computed, resulting in the Content Validity Index (CVI). Thus, CVR and CVI values of the item and instrument as whole not below .75 (sufficient with 8 SMEs) were computed (Shultz \& Whitney, 2005). The items with CVR below .75 were removed from the instrument.

After the content validation process of the tool, pilot testing was done. Subscale-wise reliability of the instrument was determined using Cronbach's alpha $(\alpha)$. Inter-item correlation was checked for the appropriate level of reliability coefficient $(\alpha)$ to establish a psychometrically sound scale with a reliability coefficient not below 0.70 accepted as credible for use in nomothetic research (Abell, Springer \& Kamata, 2009). The items with low inter-item correlations were excluded to improve the reliability of the instrument, for the final data collection.

In ensuring the validity and reliability of the instrument, 17 items were removed from the supervisor-supervisees relationship questionnaire. The subscale-wise coefficient of reliability and the sample items are given in table 2: 
Table 2

Cronbach's alpha ( $\alpha$ ) Values in Final Supervisor-Supervisee Relationship Questionnaire

\begin{tabular}{|c|c|c|c|}
\hline $\begin{array}{l}\text { SSE } \\
\text { Subscale }\end{array}$ & $\begin{array}{l}\text { No. } \\
\text { of } \\
\text { Items }\end{array}$ & $\begin{array}{l}\text { Cronbach's } \\
\text { alpha }(\alpha)\end{array}$ & Example Item \\
\hline $\begin{array}{l}\text { Project management } \\
(\mathrm{PM})\end{array}$ & 14 & .872 & $\begin{array}{l}\text { Formal meetings are/were held } \\
\text { regularly. }\end{array}$ \\
\hline $\begin{array}{l}\text { Intellectual support } \\
\text { (IS) }\end{array}$ & 16 & .943 & $\begin{array}{l}\text { 28. My supervisor gives/gave comments } \\
\text { on my written drafts. }\end{array}$ \\
\hline $\begin{array}{l}\text { Pertinent research } \\
\text { skills } \\
\text { (PRS) }\end{array}$ & 10 & .908 & $\begin{array}{l}\text { 17. My supervisor's advice } \\
\text { works/worked best whenever I stuck. }\end{array}$ \\
\hline $\begin{array}{l}\text { Interpersonal } \\
\text { communication skills } \\
\text { (IPCS) }\end{array}$ & 7 & .845 & $\begin{array}{l}\text { 40. I have/had good rapport with my } \\
\text { supervisor. }\end{array}$ \\
\hline $\begin{array}{l}\text { Workload } \\
\text { management } \\
(\mathrm{WM})\end{array}$ & 7 & .780 & $\begin{array}{l}\text { 44. I have/had to sacrifice my } \\
\text { supervision sessions due to busy } \\
\text { schedule of my supervisor. }\end{array}$ \\
\hline $\begin{array}{l}\text { Supportive } \\
\text { (SS) }\end{array}$ & 11 & .924 & $\begin{array}{l}\text { 49. My supervisor has/had introduced me } \\
\text { to different career development } \\
\text { opportunities. }\end{array}$ \\
\hline
\end{tabular}

Note. $S S E=$ Supervisees Supervision Experiences

\section{Ethical Considerations and Study Procedure}

After pilot testing of the instrument final data collection was done. More than 600 supervisees in 8 public and 4 private universities of the Punjab were contacted through the M. Phil/Ph.D program coordinators. The supervisees were approached and their consent to fill the SSRQ was taken. 422 supervisees showed their willingness to participate in the research. No single respondent was forced to complete the questionnaire without his or her consent. Supervisees were ensured that their information would be kept confidential, not disclosing their name, session or any other information that would reveal their identity except the information required to analyze the data. All the ethical considerations regarding subjects were observed.

\section{Analyses and Results}

Three research supervision related variables were selected to analyze their effect on the supervision experiences of the supervisees. The variables were categorical in nature as the supervisees were asked about the (i) alignment between the supervisor and supervisee area of research 
(ii) procedure of supervisor allotment and supervisees' and (iii) discipline of the study. We applied inferential statistics to examine the potential effect of these variables on the supervision experiences of supervisees at postgraduate level.

The influence of ancillary variables on the quality of supervision was determined by applying inferential statistics techniques, i.e. independent sample t-test and One-way Analysis of Variance (ANOVA) with eta square $\left(\eta^{2}\right)$ as measure of effect size statistics (Pallant, 2007).

\section{Supervisor-Supervisee Research Area Mismatch and Supervision experiences of Supervisees}

Table 3

Mean Scores of SSE Subscales and Supervisor-Supervisee Research Area Match

\begin{tabular}{|c|c|c|c|c|}
\hline SSE Subscale & Research Area Match & $N(333)$ & $M$ & $S D$ \\
\hline \multirow{4}{*}{$\begin{array}{l}\text { Project Management } \\
\text { (PM) }\end{array}$} & Completely different & 31 & 50.42 & 12.274 \\
\hline & Different to some extent & 56 & 51.68 & 14.456 \\
\hline & Similar to some extent & 122 & 54.65 & 11.883 \\
\hline & Exactly same & 124 & 58.05 & 12.409 \\
\hline \multirow{4}{*}{$\begin{array}{l}\text { Intellectual Support } \\
\text { (IS) }\end{array}$} & Completely different & 29 & 69.28 & 17.048 \\
\hline & Different to some extent & 54 & 67.80 & 17.198 \\
\hline & Similar to some extent & 117 & 74.69 & 16.181 \\
\hline & Exactly same & 119 & 79.44 & 15.377 \\
\hline \multirow{4}{*}{$\begin{array}{l}\text { Pertinent } \\
\text { Skills } \\
(\text { PRS) }\end{array}$} & Completely different & 30 & 42.43 & 10.569 \\
\hline & Different to some extent & 52 & 39.83 & 9.407 \\
\hline & Similar to some extent & 112 & 46.34 & 9.666 \\
\hline & Exactly same & 114 & 49.15 & 8.794 \\
\hline \multirow{4}{*}{$\begin{array}{l}\text { Inter Personal } \\
\text { Communication } \\
\text { Skills } \\
\text { (IPCS) }\end{array}$} & Completely different & 31 & 32.74 & 7.703 \\
\hline & Different to some extent & 56 & 32.88 & 7.895 \\
\hline & Similar to some extent & 119 & 35.30 & 6.986 \\
\hline & Exactly same & 121 & 38.00 & 7.112 \\
\hline Workload & Completely different & 31 & 33.32 & 7.213 \\
\hline \multirow{3}{*}{$\begin{array}{l}\text { Management } \\
(\mathrm{WM})\end{array}$} & Different to some extent & 56 & 32.30 & 7.328 \\
\hline & Similar to some extent & 123 & 34.43 & 6.546 \\
\hline & Exactly same & 125 & 36.61 & 6.488 \\
\hline \multirow{4}{*}{$\begin{array}{l}\text { Supportive Skills } \\
\text { (SS) }\end{array}$} & Completely different & 23 & 28.70 & 10.213 \\
\hline & Different to some extent & 54 & 26.70 & 9.315 \\
\hline & Similar to some extent & 111 & 31.73 & 13.029 \\
\hline & Exactly same & 107 & 35.22 & 13.237 \\
\hline
\end{tabular}


In table 3 the descriptive analyses of supervision subscales has been presented with respect to the four different categories of supervisees' research area match with respect to their supervisors' area of specialization or research. It is notable that mean score values of supervisees experiences on six supervision subscales increased as the match between the supervisees' research and supervisors' area of specialization increase. The supervisees' group which reported completely mismatched in the research area with respect to their supervisor's area of research reported the minimum mean score values on SSE subscales. The results in the above table revealed that if a supervisor supervises a research candidate in his/her own area of specialization then the supervision experiences of that supervisee will be better as compared those supervisees whose' area of research was not matched with their supervisor.

Table 4

Mean Score Comparison of Supervisees' Supervision Experiences by Supervisor-Supervisee Research Area Match

\begin{tabular}{|c|c|c|c|c|c|c|}
\hline SSE subscales & $S S$ & $d f$ & $M S$ & $F$ & $p$ & $\eta 2$ \\
\hline \multicolumn{7}{|l|}{ Project Management (PM) } \\
\hline Between Groups & 2435.536 & 3 & 811.845 & 5.133 & .002 & .045 \\
\hline Within Groups & 52039.317 & 329 & 158.174 & & & \\
\hline \multicolumn{7}{|l|}{ Intellectual Support (IS) } \\
\hline Between Groups & 6093.805 & 3 & 2031.268 & 7.795 & .000 & .069 \\
\hline Within Groups & 82086.753 & 315 & 260.593 & & & \\
\hline \multicolumn{7}{|l|}{ Pertinent Research Skills } \\
\hline Between Groups & 3503.499 & 3 & 1167.833 & 13.216 & .000 & .115 \\
\hline Within Groups & 26862.381 & 304 & 88.363 & & & \\
\hline \multicolumn{7}{|l|}{ Interpersonal } \\
\hline \multicolumn{7}{|l|}{$\begin{array}{l}\text { Communication } \\
\text { (IPCS) }\end{array}$} \\
\hline Between Groups & 1375.968 & 3 & 458.656 & 8.695 & .000 & .075 \\
\hline Within Groups & 17037.170 & 323 & 52.747 & & & \\
\hline \multicolumn{7}{|l|}{$\begin{array}{l}\text { Workload Management } \\
\text { (WM) }\end{array}$} \\
\hline Between Groups & 841.957 & 3 & 280.652 & 6.209 & .000 & .053 \\
\hline Within Groups & 14962.568 & 331 & 45.204 & & & \\
\hline \multicolumn{7}{|l|}{ Supportive Skills (SS) } \\
\hline Between Groups & 2878.874 & 3 & 959.625 & 6.327 & .000 & .061 \\
\hline Within Groups & 44138.638 & 291 & 151.679 & & & \\
\hline
\end{tabular}

Note. $S S=$ Sum of Squares, $M S=$ Mean Square, $\eta 2=$ Effect size

We performed One-way Analysis of Variance (ANOVA) to compare the mean score differences explained by the four different groups of 
supervisees which have been mentioned in table 3. It is of particular note that overall supervisees' supervision experiences significantly differ on the basis of the match or mismatch between supervisor and supervisee areas of research on the subscale of: Project Management $(p=.002)$ with medium effect size $\left(\eta^{2}=.045\right)$, Intellectual Support $(p=.000)$ with medium effect size $\left(\eta^{2}=.069\right)$, Pertinent Research Skills $(p=.000)$ with large effect size $\left(\eta^{2}=.115\right)$, Inter Personal Communication Skills $(p=.000)$ with medium effect size $\left(\eta^{2}=.075\right)$, Workload Management $(p=.000)$ with medium effect size $\left(\eta^{2}=.053\right)$, and SS $(p=.000)$ with medium effect size $\left(\eta^{2}=.061\right)$ regarding supervisees' supervision experiences (SSE). These values reveal that there is a significant difference among SSE which can be explained by the categories of supervisees who reported a "match" between their research topic and their supervisor's area of specialization with significantly $(p<.05)$ better supervision experiencesas compared to the supervisees who reported a "mismatch" between their research topic and their supervisor's area of specialization.

Table 5

Post-hoc Test of Difference of SSE Subscales for Research Area Match between Supervisor and Supervisee' Research Topic

\begin{tabular}{|c|c|c|c|c|}
\hline SSE Subscale & $\begin{array}{l}\text { (a) Match of } \\
\text { supervisee's research } \\
\text { topic with supervisor's } \\
\text { area of specialization }\end{array}$ & $\begin{array}{l}\text { (b) Match of } \\
\text { supervisee's } \\
\text { research topic with } \\
\text { supervisor's area of } \\
\text { specialization }\end{array}$ & $\begin{array}{l}\text { Mean } \\
\text { Difference } \\
\text { (a-b) }\end{array}$ & $p$ \\
\hline \multirow{2}{*}{$\begin{array}{l}\text { Project } \\
\text { Management (PM) }\end{array}$} & Completely different & Exactly same & $-7.629(*)$ & .014 \\
\hline & $\begin{array}{l}\text { Different to some } \\
\text { extent }\end{array}$ & Exactly same & $-6.370(*)$ & .010 \\
\hline \multirow{3}{*}{$\begin{array}{l}\text { Intellectual } \\
\text { Support (IS) }\end{array}$} & Completely different & Exactly same & $-10.161(*)$ & .014 \\
\hline & $\begin{array}{l}\text { Different to some } \\
\text { extent }\end{array}$ & $\begin{array}{l}\text { Similar to some } \\
\text { extent }\end{array}$ & $-6.896(*)$ & .048 \\
\hline & & Exactly same & $-11.641(*)$ & .000 \\
\hline \multirow{3}{*}{$\begin{array}{l}\text { Pertinent Research } \\
\text { Skills (PRS) }\end{array}$} & Completely different & Exactly same & $-6.716(*)$ & .003 \\
\hline & $\begin{array}{l}\text { Different to some } \\
\text { extent }\end{array}$ & $\begin{array}{l}\text { Similar to some } \\
\text { extent }\end{array}$ & $-6.512(*)$ & .000 \\
\hline & & Exactly same & $-9.322(*)$ & .000 \\
\hline \multirow{3}{*}{$\begin{array}{l}\text { Interpersonal } \\
\text { Communication } \\
\text { Skills (IPCS) }\end{array}$} & \multirow{3}{*}{$\begin{array}{l}\text { Completely different } \\
\text { Different to some } \\
\text { extent }\end{array}$} & Exactly same & $-5.258(*)$ & .002 \\
\hline & & Exactly same & $-5.125(*)$ & .000 \\
\hline & & $\begin{array}{l}\text { Similar to some } \\
\text { extent }\end{array}$ & $2.697(*)$ & .022 \\
\hline $\begin{array}{l}\text { Workload } \\
\text { Management (WM) }\end{array}$ & $\begin{array}{l}\text { Different to } \\
\text { extent }\end{array}$ & Exactly same & $-4.304(*)$ & .000 \\
\hline $\begin{array}{l}\text { Supportive Skill } \\
\text { (SS) }\end{array}$ & $\begin{array}{l}\text { Different to } \\
\text { extent }\end{array}$ & Exactly same & $-8.521(*)$ & .000 \\
\hline
\end{tabular}

* The mean difference is significant at the .05 level. 
Furthermore, a post-hoc test (Tukey HSD) was applied to report the particular groups, which were found significantly better in supervision experiences on the particular supervision subscales already mentioned in table 4 . The mean difference values for the groups, which have the same area of their research as their supervisor's area of specialization shows the positive supervision experiences as compared to the supervisees with opposite realms.

\section{Supervisor Allotment Procedure and Supervision Experiences of Supervisees}

Table 6

Mean Score Comparison of SSE Subscales by Procedure of Supervisor Allotment

\begin{tabular}{|c|c|c|c|c|c|c|c|c|}
\hline SSE Subscale & $\begin{array}{l}\text { Supervisor } \\
\text { Assignment }\end{array}$ & $N$ & $M$ & $S D$ & $\begin{array}{l}t- \\
\text { value }\end{array}$ & $d f$. & $p$ & $\eta^{2}$ \\
\hline \multirow{2}{*}{$\begin{array}{l}\text { Project } \\
\text { Management (PM) }\end{array}$} & Own choice & 219 & 56.56 & 12.415 & 3.344 & 330 & $.001\left(^{*}\right)$ & .052 \\
\hline & $\begin{array}{l}\text { By } \\
\text { department }\end{array}$ & 113 & 51.71 & 12.750 & & & & \\
\hline \multirow{2}{*}{$\begin{array}{l}\text { Intellectual } \\
\text { Support (IS) }\end{array}$} & Own choice & 212 & 77.23 & 15.052 & 3.741 & 177.677 & $.000\left(^{*}\right)$ & .059 \\
\hline & $\begin{array}{l}\text { By } \\
\text { department }\end{array}$ & 106 & 69.53 & 18.332 & & & & \\
\hline \multirow{2}{*}{$\begin{array}{l}\text { Pertinent } \\
\text { Research } \\
\text { (PRS) }\end{array}$} & Own choice & 205 & 46.99 & 9.465 & 2.994 & 305 & $.003\left(^{*}\right)$ & .040 \\
\hline & $\begin{array}{l}\text { By } \\
\text { department }\end{array}$ & 102 & 43.44 & 10.361 & & & & \\
\hline \multirow{2}{*}{$\begin{array}{l}\text { Interpersonal } \\
\text { Communication } \\
\text { Skills (IPCS) }\end{array}$} & Own choice & 216 & 36.98 & 7.009 & 4.663 & 324 & $.000\left(^{*}\right)$ & .063 \\
\hline & $\begin{array}{l}\text { By } \\
\text { department }\end{array}$ & 110 & 32.99 & 7.834 & & & & \\
\hline \multirow{2}{*}{$\begin{array}{l}\text { Workload } \\
\text { Management(WM) }\end{array}$} & Own choice & 220 & 35.16 & 7.123 & 1.531 & 331 & .127 & \\
\hline & $\begin{array}{l}\text { By } \\
\text { department }\end{array}$ & 113 & 33.95 & 6.252 & & & & \\
\hline \multirow{2}{*}{$\begin{array}{l}\text { Supportive } \\
\text { (SS) }\end{array}$} & Own choice & 199 & 32.33 & 13.200 & 1.124 & 291 & .262 & \\
\hline & $\begin{array}{l}\text { By } \\
\text { department }\end{array}$ & 94 & 30.55 & 11.368 & & & & \\
\hline
\end{tabular}

Note. (Two-tailed) $p<.05, \eta 2=$ Effect size 
We used independent sample t-test to compare the mean scores difference for Supervisees' Supervision Experiences with respect to the procedure of supervisor assignment: by department or by supervisees' own choice. It was found that overall supervisees' supervision experiences (on six subscales) for those supervisees who were allowed to select the supervisor of their own choice were better, as compared to the mean scores of supervisees who were assigned supervisors by their respective departments. Furthermore, mean score values for these two were groups significantly $(p=.001)$ different on the subscale of PM with medium $\left(\eta^{2}=.052\right)$ effect size.

Similarly, on the subscale of IS, the mean difference was significant $(p=.000)$ with medium effect size $\left(\eta^{2}=.059\right)$. Here the supervisees with supervisors of their own choice were scored higher than the supervisees assigned supervisors by their departments. Moreover, on the subscale of PRS, the mean score difference was also found to be significant ( $p=$ $.003)$ with small effect size $\left(\eta^{2}=.040\right)$.

Likewise, the same dispositions $(p=.000)$ with medium effect size $\left(\eta^{2}=.063\right)$ can be observed for the subscale of IPCS). However, no significant difference is found for the subscales of WM $(p=.127)$ and for the SS $(p=.262)$.The trend of better supervision experiences of supervisees on the subscale of WM $(M=35.16, S D=7.123)$ and SS $(M=32.33, \quad S D=13.200)$ was same as in all other subscales for supervisees who were allowed the supervisor of their own choice in comparison with the supervisees who were not involved in selecting their supervisors on the subscale of WM $(M=33.95, S D=6.252)$ and on SS $(M=30.55, S D=11.368)$. 


\section{Supervision Experiences of Supervisees in different Study Discipline}

Table 7

Discipline -wise Mean Scores of SSE Subscales

\begin{tabular}{|c|c|c|c|c|}
\hline SSE Subscale & Study Discipline & $N$ & $M$ & $S D$ \\
\hline \multirow{6}{*}{$\begin{array}{l}\text { Project } \\
\text { (PM) }\end{array}$} & Education & 82 & 54.54 & 11.549 \\
\hline & Physical Sciences & 60 & 53.72 & 12.886 \\
\hline & Life Sciences & 99 & 57.61 & 13.077 \\
\hline & Social Sciences & 64 & 54.19 & 10.979 \\
\hline & Management Sciences & 18 & 53.44 & 16.801 \\
\hline & Arts and Humanities & 9 & 56.11 & 18.611 \\
\hline \multirow[t]{6}{*}{ Intellectual Support (IS) } & Education & 81 & 75.33 & 15.012 \\
\hline & Physical Sciences & 57 & 72.63 & 16.736 \\
\hline & Life Sciences & 95 & 77.65 & 16.947 \\
\hline & Social Sciences & 58 & 73.57 & 14.445 \\
\hline & Management Sciences & 18 & 72.22 & 22.548 \\
\hline & Arts and Humanities & 9 & 79.00 & 16.194 \\
\hline \multirow{6}{*}{$\begin{array}{l}\text { Pertinent Research Skills } \\
\text { (PRS) }\end{array}$} & Education & 78 & 45.72 & 9.016 \\
\hline & Physical Sciences & 55 & 45.13 & 10.017 \\
\hline & Life Sciences & 88 & 48.11 & 10.020 \\
\hline & Social Sciences & 61 & 44.66 & 9.352 \\
\hline & Management Sciences & 18 & 44.67 & 12.485 \\
\hline & Arts and Humanities & 8 & 47.00 & $8.88,0$ \\
\hline \multirow{6}{*}{$\begin{array}{l}\text { Interpersonal } \\
\text { Communication } \\
\text { (IPCS) }\end{array}$} & Education & 81 & 36.16 & 6.875 \\
\hline & Physical Sciences & 59 & 33.68 & 7.375 \\
\hline & Life Sciences & 97 & 37.32 & 7.981 \\
\hline & Social Sciences & 62 & 34.92 & 5.877 \\
\hline & Management Sciences & 18 & 35.33 & 8.957 \\
\hline & Arts and Humanities & 9 & 35.11 & 8.313 \\
\hline \multirow{6}{*}{$\begin{array}{l}\text { Workload Management } \\
\text { (WM) }\end{array}$} & Education & 82 & 32.72 & 8.127 \\
\hline & Physical Sciences & 60 & 35.07 & 6.156 \\
\hline & Life Sciences & 100 & 36.33 & 5.920 \\
\hline & Social Sciences & 65 & 35.17 & 6.115 \\
\hline & Management Sciences & 18 & 34.00 & 8.289 \\
\hline & Arts and Humanities & 9 & 37.78 & 5.890 \\
\hline \multirow[t]{6}{*}{ Supportive Skills (SS) } & Education & 75 & 29.56 & 13.326 \\
\hline & Physical Sciences & 56 & 30.91 & 12.094 \\
\hline & Life Sciences & 89 & 34.16 & 11.674 \\
\hline & Social Sciences & 49 & 30.63 & 10.914 \\
\hline & Management Sciences & 15 & 35.27 & 18.499 \\
\hline & Arts and Humanities & 9 & 40.11 & 12.108 \\
\hline
\end{tabular}

Note. $N=$ No. of supervisees, $M=$ Mean score, $S D=$ Standard deviation 
The SSE in six different disciplines is given with their mean scores and standard deviation values on six supervision subscales in table 7. The faculty-wise descriptive analysis of supervision subscales presents a general overview of the average supervisees' experiences in comparison with the different disciplines simultaneously. It can be observed from the overall mean scores of the supervisees' experience about the six supervision aspects of their supervisors in life sciences discipline are found better found better as compared to the supervisees in other disciplines.

Table 8

Discipline-wise Comparison of Supervisees' Supervision Experiences (SSE) Subscales

\begin{tabular}{|c|c|c|c|c|c|c|}
\hline SSE subscales & $S S$ & $d f$ & $M S$ & $F$ & $p$ & $\eta^{2}$ \\
\hline \multicolumn{7}{|l|}{ Project Management } \\
\hline Between Groups & 869.656 & 5 & 173.931 & 1.080 & .371 & \\
\hline Within Groups & 52523.293 & 326 & 161.114 & & & \\
\hline \multicolumn{7}{|l|}{ Intellectual Support } \\
\hline Between Groups & 1391.918 & 5 & 278.384 & 1.042 & .393 & \\
\hline Within Groups & 83344.135 & 312 & 267.129 & & & \\
\hline \multicolumn{7}{|l|}{ Pertinent Research Skills } \\
\hline Between Groups & 590.410 & 5 & 118.082 & 1.236 & .292 & \\
\hline Within Groups & 28862.538 & 302 & 95.571 & & & \\
\hline \multicolumn{7}{|l|}{$\begin{array}{l}\text { Interpersonal Communication } \\
\text { Skills }\end{array}$} \\
\hline Between Groups & 555.495 & 5 & 111.099 & 2.082 & .067 & \\
\hline Within Groups & 17074.373 & 320 & 53.357 & & & \\
\hline \multicolumn{7}{|l|}{ Workload Management } \\
\hline Between Groups & 689.848 & 5 & 137.970 & 3.038 & $.011(*)$ & .044 \\
\hline Within Groups & 14895.086 & 328 & 45.412 & & & \\
\hline \multicolumn{7}{|l|}{ Supportive Skills } \\
\hline Between Groups & 1770.928 & 5 & 354.186 & 2.266 & $.048(*)$ & .038 \\
\hline Within Groups & 44860.041 & 287 & 156.307 & & & \\
\hline
\end{tabular}

Note. $S S=$ Sum of Squares, $M S=$ Mean Square, $\eta^{2}=$ Effect size

* Mean difference is significant at the $(p) .05$ level

We performed ANOVA to compare the SSE in six different disciplines which have been mentioned in table 8. It is reported that the mean score of supervisees' experiences from the different disciplines of the study are significantly different $(F=3.038, p=.011)$ on the subscale of WM with small effect size (.044). Further, a significant difference $(F=$ $2.266, p=.048)$ is also found with small effect size (.038) on the subscale 
of SS. These values reveal that there is a significant difference among the SSE from different disciplines.

Table 9

Post-hoc Test of Difference of SSE Subscales for Multiple Disciplines

\begin{tabular}{lllll}
\hline & & Mean & $p$ \\
SSE Subscale & Discipline & Difference & \\
& Discipline(a) & (b) & $(\mathrm{a}-\mathrm{b})$ & \\
\hline Workload Management $(\mathrm{WM})$ & Education & Life Sciences & $-3.610(*)$ & .005
\end{tabular}

* Mean difference is significant at the $(p) .05$ level

Furthermore, a post-hoc test (Tukey HSD) was performed to report that what particular disciplines were significantly different in the SSE on the subscale of WM. The mean difference value $(M D=-3.610, p=.005)$ for Education and Life Sciences disciplines shows that supervisees in the discipline of Life Sciences have better supervision experiences with their supervisors about spending appropriate time and managing their different activities in research supervision of their supervisees as compared to the supervisees in the Education discipline.

\section{Discussion and Implications of the Study}

We conducted this research to analyze the influence of research related background variables on the supervision experiences of supervisees as a matter of determining quality of supervision with different supervision aspects from the perspective of supervisees. By ensuring the synergy between relevant background variables, the findings of the study can indicate effective efforts to improve quality of research supervision based on the comprehensive framework of supervision aspects.

\section{Research Expertise of Supervisor and Supervision Experiences of Supervisees}

As part of background profile of supervisees the effect of the extent to which the supervisors have research expertise in their supervisees' research topics on the supervisees' supervision experiences. Match between supervisor research expertise and research topic of a supervisee was found the most significant supervision related variable that influence 
the supervision experiences of supervisees. It was observed in the table values that across all the analyzed supervision aspects of supervisors from the perspective of supervisees, we found significantly better supervision experiences of supervisees who were working on research topics which matched to their supervisors' area of specialization or area in which their supervisors have some published work. Hence, the lack of a supervisor's research competence in the supervisee's research topic can have a negative influence on the overall supervision experiences. Supervisees who have such research area mismatches evidently suffer while developing, designing, conducting and reporting their research within the boundaries of their related topic.

Furthermore, a possible reason behind the poor supervision experiences of supervisees with such a mismatch with their supervisor is the lack of any supervision guidelines, trainings or any other mechanism at the institutional or policy level that can ensure the basic research knowledge and expertise of supervisors to serve in the potential domains of their specific discipline for maintaining the quality of supervision.

Moreover, the concept of team supervision is not so prevalent in the Pakistani context especially in the social sciences disciplines. As a result, a supervisor is the sole support for supervisees. So, in this situation the only thing which can improve the supervision experiences is the supervisor's being knowledgeable or having research skills in the supervisee's research topic. This might be the main concern in the supervisory relationship, especially from the perspective of supervisees in our context.

Likewise, while studying the similar background variables in the Australian context, Ives and Rowley (2005) found the importance of a match between a student and the supervisor in their interpersonal working patterns and research methodology in a positive way. However, in our context, the lack of intra-disciplinary research expertise of supervisors is a source of potential supervision issues for the supervisees with a different area of research.

On the other hand, the lack of proper knowledge and research expertise of supervisors in their supervisees' research topic may also be considered as a barrier towards the generation of new knowledge and contribution to the existing body of knowledge. As a consequence, the usability of research produced by such combination of supervisor and supervisee will lead to a cycle of deterioration. Hence, acknowledging the importance of a supervisor's being knowledgeable and skillful about the supervisees' area of research can be considered as one of the most 
important indicators of research supervision which significantly influences the supervisees' supervision experiences at postgraduate level.

\section{Supervisor Allotment Procedure and Supervision Experiences of Supervisees}

Moreover, in this survey we found that one third of the respondents have been allocated supervisors by the decision of their respective departmental doctoral committees instead of their own choice. However, we investigated empirically, that selecting a supervisor of the own choice of supervisees can positively impact the supervision experiences of supervisees with respect to the personal and psychological satisfaction of supervisees. In addition, Ives \& Rowley (2005) have also found in favor of selecting the supervisor by supervisee's own choice and expressing the importance of other concerned areas, i.e., related to the selection of research topic and potential personality clashes which usually happen in cases when the supervisees do not have choice to select their supervisors independently.

However, the selection of supervisor is an important step for a supervisee according to Phillips \& Pugh (2010) and that can be declared as one of the most important transactions in supervision experiences. The supervisees' choice in the supervisor assignment procedure gives them a liberty in selecting a supervisor based on the established research record and how close a working relationship a supervisee wants.

It also puts a positive psychological effect to work with supervisor of their own choice in making supervision experiences more satisfying for the students who are involved in the supervisor selection procedure as compared to the students who don't get this opportunity.

In a Canadian research study Donald, et al. (1995) found these two factors significant related to the supervisor's knowledge about the research field and their availability as reported by program directors across the different disciplines in graduate research supervision. But, in the case of by-department assignment of supervisors, there may also be a possibility to ignore this relevant factor of a supervisor being knowledgeable about the supervisee's research field.

In addition, Holloway et al. (1995) declared the findings of their research in favor of involving students in the selection of supervisors. However, in the academic culture of Pakistani higher education institutions, one of the reasons behind the assignment of supervisors by departmental doctoral program committees is the substantial increased 
number of supervisees compared to the number of supervisors available. This could necessitate the assignment of supervisors by departmental decisions without involving students in order to avoid having one or two supervisors selected by too many students, creating a significant workload distribution problem.

\section{Supervision Experiences of Supervisees in different Study Discipline}

While analyzing the supervision experiences of supervisees from the six different disciplines, we found that the supervisees from the faculty of Life Sciences have reported greater supervisor's support in resourcing their supervisees' research projects, while accommodating them with in meeting standards of evaluation and providing them with career development opportunities as compared to supervisees from the Education discipline who do not enjoy such support from their supervisor. The difference is likely due to the fact of a laboratory-based research culture in the Life Sciences' discipline in which there is more probability of frequently having formal and informal supervisory consultations hence increasing the supervisors supportive involvement in supervisees' research related problems relative to the supervisees from the education discipline.

In the disciplines of education and social sciences, the supervisors' and supervisees' work in different places and may have research projects with their separate diverse research interests which may possibly be a source of gap between supervisor and supervisee interaction. As Cullen, et al. (1994) also found, supervision nature and style of supervisors varies across the different disciplines in that supervisors from science disciplines provide more close styles of supervision as compared to the supervisors in social sciences.

Another possible reason for this difference in the supportive supervisory approach is the culture of project based supervision practices which exist in the life sciences discipline in our context. In this context, supervisors involve students in their working projects hence they become more concerned and supportive for their supervisees and spend appropriate time in supervision due to their mutual interest in the successful completion of the research projects. This significant finding underscores the need for introducing a project-based research culture in those disciplines where the supervisors and supervisees can share some mutual interests and benefits for successful production of research. 
Consequently, supervisees from these two different disciplinary extreme realms also showed a significant difference in the completion time and rate in their research studies. The conclusions are also in line with a research study conducted by Seagram, Gould \& Pyke (1998) who found the mean completion time for the Natural Science discipline area was 4.86 years, for Humanities 6.39 years, and for Social Science 6.58, revealing the faster study completion in the Natural Sciences.

Moreover, the supervisees' collaborative and supportive experiences are reported with the highest frequency of meetings with their supervisors in Life Sciences as compared to the supervisees' experiences in the Humanities. Hence, these important findings related to disciplinary differences in the supervision experiences of supervisees may also be due to different supervision approaches. This again supports the idea of encouraging project-based $\mathrm{PhDs}$ that can improve supervision practices in the disciplines of Education, Social Sciences and Humanities. Meanwhile, at the institutional level there is a need to devise and monitor the teaching and supervision workload schedules for supervisors when performing formal and informal institutional responsibilities other than supervision when the management of workload becomes a crucial problem for supervisors.

\section{Conclusion and Recommendations}

The findings of the research can present a number of implications for policy makers, doctoral program committees and research supervisors at postgraduate level. At the policy level, supervisors can be developed through discipline-specific supervision guidelines according to the phase-wise research activities in order to minimize the research related unproductive efforts on the part of supervisees. It is critically important to ensure the alignment between the supervisor's area of specialization and supervisee's research topic. There can be devised workload modules for supervisors to manage an appropriate number of supervisees and to monitor the working progress of supervisees while avoiding the late completion of thesis as well. On the basis of findings it is suggested that departmental doctoral programmes committees may ensure the supervisor' allotment procedure to be done with the mutual agreement between supervisor and supervisee. In house seminars, workshops or training programmes for supervisors may be initiated to equip them with discipline specific research methods in order to manage the large diversified pool of supervisees from the different and new emerging fields under a discipline. 


\section{References}

Abell, N., Springer, D. W., \& Kamata, A. (2009). Developing and validating rapid assessment instruments. New York: Oxford University Press.

Abiddin, N. Z., Ismail, A., \& Ismail, A. (2011). Effective supervisory approach in enhancing postgraduate research studies. International Journal of Humanities and Social Science, 1(2), 206-217.

Connell, R.W. (1985). How to supervise a PhD. Vestes,2, 38-41.

Cullen, D.J., Pearson, M., Saha, L.J., \& Spear, R.H. (1994). Establishing effective Ph.D. supervision. Canberra: Australian Government Printing Service.

Donald, J. G., Saroyan, A. \& Denison, D. B. (1995). Graduate Student Supervision Policies and Procedures: A Case Study of Issues and Factors Affecting Graduate Study. The Canadian Journal of Higher Education, 25(3), 71-92.

Eley, A., \& Jennings, R. (2005). Effective Postgraduate Supervision: Improving the Student/Supervisor Relationship. London: McGrawHill International.

Grant, B. (2003). Mapping the pleasures and risks of supervision. Discourse: Studies in the Cultural Politics of Education, 2, 175-190.

Halai, N. (2011). Becoming and being a doctoral supervisor in Pakistan: A lived Experience. In V. Kumar and A. Lee (Eds.), Doctoral Education in International Context: Connecting Local, Regional and Global Perspectives (pp.37-49). Malaysia: Malaysia Press.

Higher Education Commission, Pakistan (HEC, 2015). Higher Education Institutions Statistics. Ph.D and non-Ph.D full time faculty by region during 2012-13. Retrieved from http://www.hec.gov.pk/InsideHEC /Divisions/QALI/Others/Pages/StatisticalInformationUnit.aspx

Holloway, E. L. (1995). Clinical supervision-system approach. California: SAGE. 
Iqbal, M.Z., Saeed, M. \& Abbas, F. (2012). Problems in public sector universities of Punjab: Views of $\mathrm{PhD}$ scholars. International Researchers, 1 (3), 1-13.

Ismail, A., Abiddin, N. Z., \& Hassan, A. (2011). Improving the development of postgraduates' research and supervision. International Education Studies, 4(1) 78-89.

Ismail, H. M., Majid, F. A., \& Ismail, I. S. (2013). It's complicated Relationship: Research Students' Perspective on Doctoral Supervision. Procedia-Social and Behavioral Sciences, 90, 165-170.

Ives, G. \& Rowley, G. (2005). Supervisor selection or allocation and continuity of supervision: Ph.D students' progress and outcomes. Studies in Higher Education, 30 (5), 535-555.

Javed, U. (2014, January 6). Reversing the rot. Dawn News. Retrieved from http://www.dawn.com/news/1078612

Kam, H. K. (1997). Style and quality in research supervision: the supervisor dependency factor. Higher Education, 34, 81-103.

Lawshe, C.W. (1975). A quantitative approach to content validity. Personnel Psychology, 28, 563-575.

Lee, A. (2008). How are doctoral students supervised? Concepts of doctoral research supervision. Studies in Higher Education, 33(3), 267-281.

Lynch, S. (2008). Happy days: Why PhD students need a helping hand from their supervisors. Retrieved from http://www.independent. co.uk/news/education/ higher/happy-days-why-phd-students-need-ahelping-hand-from-their-supervisors-781842.html

Mahmood, S. T. (2011). Factors affecting the quality of research in education: Students' perceptions. Journal of Education and Practice, 2 (11 \& 12), 34-39.

Nevada, V.L. (2009). Research in Indian Universities: A Critical Analysis. Retrieved from http://www.cluteinstitute.com/Programs /Las_Vegas_2009/Article\%20267.pdf 
Noor, M. (2013, July 17).The Express Tribune. Retrieved fromhttp://tribune.com.pk/story/577780/intellectual-boom-pakistanis-publishing-more-research-papers-per-capita-than-india/

Pallent, J. (2007). SPSS survival manual: A step by step guide to data analysis using SPSS for windows. Australia: Allen \& Unwin.

Phillips, E. M. \& Pugh, D. S. (2010).How to get a PhD: A handbook for students and their supervisors. United Kingdom: McGraw-Hill Education.

Pearson, M. (2005). Framing research on doctoral education in Australia in a global context. Higher Education Research \& Development, 24(2), 119-134.

Quality Assurance Agency for Higher Education. (QAA, 2004). Code of practice for the assurance of academic quality and standards in higher education: Postgraduate research programme. United Kingdom: QAA Publications.

Saleem, T. (2014). Impact of supervisor-supervisee relationship on the quality of supervision at postgraduate level. Unpublished MPhil thesis, submitted at University of the Punjab, Lahore.

Seagram B., Gould, J., \& Pyke, S. (1998). An investigation of gender and other variables on time to completion of doctoral degrees. Research in Higher Education, 39 (3), 319-335.

Shultz, S.K. \& Whitney, D.J. (2005). Measurement theory in action. UK: Sage Publication.

Spear, R. H. (2000). Supervision of research students: Responding to student expectations. Canberra:The Australian National University.

Taylor, S., \& Beasley, N. (2005). A handbook for doctoral supervisors. United States of America: Routledge.

Virk, M. (2003). Universities of Pakistan. Pakistan: UGC publications.

Wisker, G. (2005). The good supervisor: Supervising postgraduate and undergraduate research for doctoral theses and dissertations. Retrieved from http://philpapers.org/rec/WISTGS 
Yousaf, F. \& Ashraf, S. (2010). A study of supervision issues faced by doctoral (MPhil/PhD) students in a supervisor-supervisee relationship. Unpublished Master's thesis, University of the Punjab, Lahore.

\section{Citation of this Article:}

Saleem, T., \& Mahmood, N. (2017). Influence of the supervision related background variables on the supervisees' supervision experiences at postgraduate level. Pakistan Journal of Education, 34(2), 73-99.

Received on: March 30, 2017

Revised on: November 09, 2017

Accepted on: November 24, 2017 